\title{
Review of An Integrated Air-Vinasse Treatment-To-Food, Energy, Water, And A Novel Mosquito-Combatant Soil Amendment
}

Lucina Kuusisto*

Department of Biological \& Environmental Sciences, Texas A\&M University-Commerce, USA

\begin{abstract}
Industrial waste has been an international concern for decades. In addition to pollution concerns, other problems assailing humanity include global hunger, lack of clean water in many parts of the world, and the rising cost of energy production. In order to remediate an environmental pollution issue, and, simultaneously, to generate three main items that are essential to humanity, the novel Integrated AirVinasse Treatment-to-Food, Energy, Water, and a Novel Mosquito-Combatant Soil Amendment was conceptualized [1]. This report reviews the said novel integrated air-vinasse treatment-to-co-products process: TAOS (Three and One Significant products). In this study, other vinasse treatment alternatives are also reviewed. A succinct description of the five main stages of the TAOS process is summarized. Biogas treatment technologies are reviewed. The novel concept of a vinasse-generated mosquitocombatant fertilizer is revealed. A process flow diagram of the TAOS process is shown.
\end{abstract}

Keywords: Food; Energy; Water; Vinasse; Treatment; Vectors; Mosquitoes; Virus; Health

*Corresponding author: Lucina Kuusisto, Department of Biological \& Environmental Sciences, Texas A\&M University-Commerce, Texas, USA

Submission: 非 February 24, 2019

Published: March 6, 2020

Volume 2 - Issue 3

How to cite this article: Lucina Kuusisto. Review of An Integrated Air-Vinasse Treatment-To-Food, Energy, Water, And A Novel Mosquito-Combatant Soil Amendment. J Biotech Biores.2(3). JBB.000538.2020.

Copyright@ Lucina Kuusisto, This article is distributed under the terms of the Creative Commons Attribution 4.0 International License, which permits unrestricted use and redistribution provided that the original author and source are credited. waste. Ethanol is a major biofuel. One of the co-products from ethanol production is vinasse

\section{Introduction}

In the past few decades, innovative reclamation technologies have been developed to treat pollutants and generate useable byproducts. Current sustainability concerns promote increased production of biofuels. The revised Renewable Fuel Standard (RFS) promotes blending of biofuels with conventional motor fuels, and it supports the production of 36 billion gallons of biofuels per year by 2022. The increase of biofuel production results in an abundance of waste coproducts. These trends imply that greater quantities of biofuel co-products are generated, thus requiring further treatment and disposal of the industrial or stillage. Ethanol distilleries produce, approximately, 12 gallons of stillage (or vinasse) per gallon of ethanol [2]. Currently, in the United States, vinasse treatment and disposal include producing Dried Distillers Grains (DDGs) to use as animal feed. These coarse corn particles, also called "Distillers Grains", have not yet been widely used as a source of food for humans.

\section{Food shortage}

According to the United Nations' yearly report on world food security and nutrition, 2018, global hunger affected over 800 million people. According to Milesi et al. [3], Julio Berdegué, the regional representative for Latin America of the Food and Agriculture Organization of the United Nations (FAO) [4], said that the number of hungry people in Latin America and the Caribbean have increased to 39.3 million people, an increase by 400,000 since 2016. In addition to the rising number of hungry people, due to the low availability of nutritious food at affordable prices, there is a paradox of a rising number of obese children. A report from the Food and Agriculture Organization of the United Nations, as referred to by Labatut B et al. [5], states that in Latin America and the Caribbean, the majority of the people suffering from hunger, malnutrition, lack of micronutrients, and, the paradox of obesity, include women, people of lower income, indigenous people, Afro-descendants, and rural families. Malnutrition problems may have catalyzed the idea of fortifying staple foods into action. Studies about fortifying staple food items and its effects on human health have been performed along recent decades. According to Bishai D et al. [6], in the United States, "the enrichment of flour and bread started in the 1940s". Fortifying food may seem to be a logical good idea. 
According to De-Regil L et al. [7], the many processes undergone by the maize [corn] to produce cornmeal or corn flour may deplete its overall nutrition value [8] in a study about wheat flour fortification with folic acid, concluded that wheat flour fortification might have contributed to the reduction of neuro tube defects. There seems to be a contradiction between fortifying staple food, health improvement, and hunger, versus obesity. According to Dwyer J et al. [9] there are risks and benefits to fortification of food. According to the USDA (United States Department of Agriculture), (2012), the common method for preparing cornmeal is by milling shelled corn. In the United States, cornmeal is a coarse-type of flour, and it is, usually, prepared after grinding clean, dried corn. During the usual processing, most of the bran and germ are removed. In the United States, in order to add to nutritional value of the cornmeal, thiamin, niacin, riboflavin, folic acid, iron, and, sometimes, calcium and vitamin D are added to the cornmeal. It is relevant to continue studying fortification of staple foods, and the outcomes. Future studies should focus on the pros and cons of adding certain types of micronutrients, and certain particles and nanomaterials.

\section{Increased need of sustainable energy production}

The utilization of ethanol as biofuel seems to be a viable solution for sustainable development. As previously discusses, the manufacturing of ethanol also produces vinasse. In many countries, vinasse is an environmental problem. In the US, the main feedstock for ethanol manufacturing is corn. Treatment solutions that convert industrial waste into useable products are important opportunities for recycling valuable substances and generating energy, as well as combating environmental pollution. Therefore, instead of disposing vinasse as a pollutant, scientific research has been done to valorize the vinasse, and it has been demonstrated that vinasse may be used as a feedstock to generate biogas [10]. Wilkie et al. [11] presented a thorough review of different types of vinasse treatment, which included: Physical/mechanical separation; Single cell protein; Algae as well as other byproducts production; and Anaerobic treatment of vinasse, among others. Satyawali et al. [12] reviewed the existing status and advances of various treatment methods. He stated that anaerobic treatment was the most attractive primary treatment due to the BOD removal rate being over $80 \%$, in addition to the energy recovery in the form of biogas. His work focused on various:

\section{A. Biological methods, and}

B. Physicochemical methods such as adsorption, coagulation/precipitation, oxidation, and membrane filtration. Moraes et al. [13-15] and Ribas et al. [16] advocated the advantages of anaerobic digestion because of its effective reduction of the organic load and because it produces biogas. The anaerobic treatment serves two main purposes: the reduction of the organic load as well as the generation of useful biogas. Wilkie et al. [11], listed the Up-flow Anaerobic Sludge Blanket (UASB) reactor as advantageous. He concluded that the thermophilic anaerobic digestion of the vinasse could be achieved in smaller reactors, in addition to having higher reaction rates. Furthermore, with this type of treatment, methane can be recovered and used as fuel.

\section{Lack of clean water}

According to Vörösmarty et al. [17], almost $80 \%$ of the world's population lack clean water. Current demands on freshwater resources are increasing, and ground water supplies have been over-extracted in many regions of the world by human activities [18]. Many factors play different roles in this concerning clean water shortage situation, including population growth, urbanization, and economic development [19]. These humanity issues pose increasing pressure to find solutions for water pollution and shortage. Reclaiming water, and innovative treatment alternatives are realistic solutions for this current worldwide problem.

\section{Fertilizers}

The application of fertilizers to enhance crop yield has been practiced for many centuries. The main chemical components included in fertilizers are N, P, and K (nitrogen, phosphorus, and potassium). These main components are present, though in different ratios, in the vinasse chemical composition from any feedstock. Although there are some differences in the processing of sugar, starch and lingo-cellulosic feed-stocks for ethanol production, many aspects of the vinasse composition are the same [11]. Although the main purpose for applying fertilizers to agricultural fields is to enhance crop yield, recent scientific studies have shown that the application of fertilizers to the soil also enhance biotechnological processes using microbes for the degradation of toxic compounds in the soil. In order to remove environmental pollutants from the soil, bio-remediation processes use microorganisms to decompose organic and inorganic components from the soil, water, and sediments Pala et al. [20], as referred by Chorom M et al. [21]. According to Van Gestel et al. 2001; Gogoi et al. 2003; Nano et al. 2003; Morelli et al. 2005; Demnerová et al. 2005, as referred to by Chorom $\mathrm{M}$ et al. [21], bio-remediation processes have many advantages over other pollution removal processes, e.g., extraction with solvents, and the addition of chemical oxidizers. Furthermore, Bardi et al. 2000; Semple et al. 2001; Sabate et al. 2004; Ghazali et al. 2004; Walter et al. 2005; Atlas and Bartha, 2006, as referred to by Chorom $\mathrm{M}$ et al. [21], have concluded that the addition of nutrients, such as nitrogen or phosphorus or both could accelerate the decomposition of crude oil from seawater. In addition, Vasudevan and Rajaram, 2001; Gogoi et al. 2003; Coulon et al. 2005; Ayotamuno et al. 2006; Sang-Hwan et al. 2007, as referred to by Chorom M et al. [21], have investigated the effects of nutrients (i.e. N, P, K), in addition to other pertinent bioremediation techniques to treat oil contaminated soil. Ayotamuno et al., 2006, concluded, as referred to by Chorom $\mathrm{M}$ et al. [21], that the quantities of fertilizer ( $\mathrm{N}, \mathrm{P}, \mathrm{K}$ ), moisture, and tillage were crucial for an effective bioremediation.

\section{Pests and public health issues}

In humid and temperate-climate locations, mosquitoes breed easily. Mosquitoes are known to be vectors of diseases. Mosquito- 
borne diseases include Zika, Chikungunya, and Dengue (CDC, 2018). The TAOS process yields a novel vinasse-derived fertilizer containing mosquito repellent and combating agents. This fluid fertilizer may combat the spreading of diseases transmitted by mosquitoes.

\section{Overall Description of The Taos Process}

In order to minimize the environmental pollution caused by vinasse, and, simultaneously, utilize its beneficial components, this process was conceptualized. The aforementioned process integrates five main stages.

The advantageous outcomes from this process include:

A. Recover and fortify cornmeal with a novel formulation

B. Generate energy from the combustion of methane

C. Reclaim distilled water

D. Produce a grade "A" liquid fertilizer, containing a novel "virus-dismantling" formulation

E. Filter biogas with novel filtering materials and Filter the combustion engine-exhaust gases.

The current, cutting-edge vinasse treatment processes do not reclaim food for humans nor generate a disease-combating product.

TAOS aims at generating at least two novel products from vinasse, which are:

A. Human food, and

B. A thick liquid [non-Newtonian fluid] fertilizer that may combat the spreading of diseases by, physically, trapping mosquitoes, and, biochemically, dismantling some viruses carried by mosquitoes.

\section{Positive Aspects of The Taos Process}

TAOS is an integrated treatment process that includes the following stages

\section{Recovery, formulation, and fortification of cornmeal}

The food is fortified cornmeal, and it is obtained by processing, e.g., rinsing, centrifuging, promoting Ultraviolet light treatment, dehydrating, and fortifying corn-ethanol vinasse. The recovery of cornmeal is to be processed prior to the anaerobic digestion of vinasse. Other main tasks at this specific stage includes adding a calculated amount of plant-based protein, polyunsaturated fatty acids, and other micronutrients, e.g., niacin, ferrous sulfate, thiamine mononitrate, riboflavin, folic acid, to the cornmeal.

The main objectives for this stage include:

A. Decrease hunger in many countries by increasing the quantity of food supply

B. Increase the availability of good quality food by producing this uniquely formulated satiating food, by adding healthy plant-based fats contained in polyunsaturated fatty acid to its composition

C. (Valorize the corn-ethanol vinasse to produce food for humans, instead of, mainly, being used to produce animal feed

D. Reclaim a staple food

\section{Generation of biofuel from the anaerobic treatment of} vinasse

The second stage of this process provides the anaerobic decomposition of the liquid portion of the

vinasse, after it has undergone centrifugation. The anaerobic treatment serves two main purposes: the reduction of the organic load as well as the generation of biofuel.

\section{Filtration of biogas before combustion. Then, cleaning the exhaust gases after the combustion of methane}

This is a dual-phase gas treatment facility: First, clean the biogas with a filter containing Powdered Activated Carbon (PAC) and a 'green' sorption media to recover the methane. Then, treat the exhaust gases from the gas-combustion engine, resorting to atomizing nozzles conveying aqueous solution containing organic acids to neutralize ammonia and other nitrogen compounds, before the emission of the gases into the atmosphere. In a generalized manner, air pollutants may be divided according to the physical state in which they occur: particulate matter, gases, and vapors. Particulate matter may be classified according to their formation method: dust (cement, asbestos, cotton or the street); fumes (lead, aluminum, zinc chloride, ammonia); mists (liquid particles); and smoke (particulate from burning fossil fuels, asphalt material or wood, soot, or ashes). Gases and vapors are pollutants in molecular form and may also cause nuisance odors or contain highly polluting toxic materials, such as dioxins and furans.

In the case of the TAOS system, after the biogas is treated, the recovered methane is sent to a combustion engine to co-energize the evaporation of the supernatant from the bio-digester. Then, the exhaust gases from the engine are sent to an atomizing nozzle system, supplied with an aqueous solution containing organic acids to neutralize ammonia, hydrogen sulfide, and traces of other pollutants. According to Verbeeck K et al. [22,23], the chemical composition of the aqueous solution should include esters originating from long-chain fatty acids to aid in the neutralization of hydrogen sulfides and other volatile sulfides.

\section{Reclamation of distilled water from the evaporation of the supernatant}

During this stage, the supernatant from the anaerobic reactor is sent to a multi-effect evaporator coupled with a condensation unit. The evaporation of the supernatant achieves two main goals: The first reason is to reclaim distilled water. The second reason is to produce a fertilizer that is denser, and has higher viscosity, thus rendering a fertilizer that also serves as a mosquito trap, 
therefore, decreasing the motion of disease-vectors. Furthermore, the concentrated fertilizer, in small size containers, requires less transportation cost, and it is easier to handle and apply. In addition, it is more time-efficient to add this novel "mosquitocombating" feature to the concentrated fertilizer. The rationale for implementing this anti-mosquito formulation in the fertilizer is to decrease the spread of some viruses, carried by mosquitoes in the environment.

\section{Production of a grade "A" fluid fertilizer, modification of the supernatant rheological properties, formulation of novel "mosquito-combating" fertilizer}

This stage involves the concentration of the supernatant from the anaerobic reactor to $40-60 \%$ of solids per unit volume. During the trajectory of the vinasse throughout this phase, the rheological characteristics will be modified. The supernatant becomes a NonNewtonian fluid, which is a practical property because, after the water evaporation, this fluid occupies less volume, thus enabling the fluid storage in easy-to-handle small-size containers. In addition, a novel formulation will yield a multi-action fertilizer that will help the farmer enhance food production. This fertilizer, a thick liquid, non-Newtonian fluid, can combat the spreading of diseases by, physically, trapping mosquitoes, and, biochemically, dismantling some viruses carried by the trapped mosquitoes.

\section{Various Approaches to Vinasse Treatment}

In the last few decades, many researchers have studied different approaches to vinasse treatment. The following review lists some of the main processes for vinasse treatment and disposal. Cortez LAB \& Brossasd Pérez LE, Brossard [24] investigated and developed the basic technology of on-site disposal of vinasse by combustion. His research consisted of determining heating values, composition, and flame characteristics through combustion tests. Initially, he used only vinasse with different solid concentrations and, later, he used emulsions of vinasse and \#6 fuel oil. He stated that the purpose of his research was to evaluate the technical feasibility of vinasse combustion via atomization.

He derived his conclusions from two different perspectives:

Rheological and Combustion.

A. From the rheological perspective, he stated that for both categories of his trials, i.e., the vinasse by itself and the emulsions of vinasse combined with \# 6 fuel oil, had rheological behavior close to the \# 6 fuel oil alone, when tested in the Brookfield Rotary Viscometer. After the right temperature and shear rate were obtained, he did not have any problems obtaining atomization and combustion. He used vinasse with the solid's concentration below $50 \%$ for the combustion tests.

B. From the Combustion perspective, he stated that the combustion of the emulsions prepared with vinasse plus \# 6 fuel oil is feasible in the range from $95 \%$ of \# 6 fuel oil and $5 \%$ of vinasse to $50 \%$ of \# 6 fuel oil to $50 \%$ of vinasse. He stated that, beyond that range, the flame was unstable and not compact. He found out that the best results were obtained when 95 to $75 \%$ \# 6 fuel oil were used together with 5 to $25 \%$ of vinasse.

The drawbacks he listed included:

i. $\quad$ The energy needed for the vinasse pre-evaporation was quite high.

ii. When concentrating to up to $75 \%$ of solids, the foaming in the evaporators was another problem.

iii. The crystallization of salts in the syrup causes difficulties with the operations of certain appurtenances.

Many alternatives for the treatment of vinasse have been studied, such as: aerobic processes in ponds $[25,26]$ sequential batch reactor with activated sludge [27]. Ribas (2006) has stated that the anaerobic reactors have shown to be a great alternative because they accomplish a high rate of organic load removal and produce biogas.

\section{Physico-chemical methods}

These methods use ways to enhance flocculation, change the $\mathrm{pH}$, modify the temperature, remove color and turbidity. Gonçalves et al. [28] performed a research for the treatment of the vinasse by utilizing coagulation and flocculation by utilizing the factorial planning technique. She evaluated several variables, specially, the COD removal. Then, she developed a statistical model representing the process., neglecting the variables of less significance. The traced areas originated by the model, demonstrated that the COD removal varied as a function of the $\mathrm{pH}$ and of the parameters from the rapid mixing. The best results were achieved when calcium oxide and ferrous sulfate were used, with the $\mathrm{pH}$ values near 12.41, and the removal were 52 and $44 \%$, respectively. She observed that the resulting sludge could be used as a fertilizer because it was rich in nutrient content. She concluded that the statistical planning technique was very useful in the evaluation of the efficiency of the COD removal, even with the simultaneous variation of more than one variable, in addition to enabling the possible interactions among the variables. She recommended a study about the financial feasibility of that type of treatment in an industrial scale.

Fernández $\mathrm{N}$ et al. [29] used activated carbon and natural zeolite as support materials, in their research for vinasse treatment in an anaerobic fluidized bed reactor. He stated that, in Cuba, the vinasse is a very strong pollutant. In addition to iys high organic load, it has a high content of sulfates. In his research, when he applied the anaerobic technology, most of the biodegradable organic matter turned into biogas, specially, methane. The problem he had was the unwanted concentration of sulfides, which was above $1 \%$. In his work, he developed two experiments with anaerobic fluidized bed reactors (AFBR), using easily available in Cuba raw materials: (1) activated carbon and (2) natural zeolite, as support media. The purpose of his research was to achieve high removal rates for the organic matter, while maintaining the concentrations of sulfides and ammonium within the permissible ranges. In his research, the reactors were operated for 120 days. His experiment achieved 
an organic loading rate of $10 \mathrm{kgCOD} / \mathrm{m}^{3}$ day, with COD removal above $70 \%$. The methane production was $2 \mathrm{~L} / \mathrm{d}$. He stated that the activated carbon and natural zeolite, used as support materials in the anaerobic fluidized bed reactors, showed good results for waste removal.

\section{Biological methods}

These biochemical methods are used in order to accelerate the degradation of the organic matter in the fluid. The degradation is accomplished by microorganisms. The bacteria, rotifers, and protozoa are the main microorganisms used by this method. After digestion, the following are produced: a clearer liquid, sludge , and methane gas. This type of treatment use reactors which are designed to hold the wastewater for a specific interval, the detention time. These reactors enable the composition and the concentration changes. The mass balance in the reactors vary, in accordance with the variation of the hydraulic flux in the reactor and the kinematics of the biochemical reactions.

Tewari et al. [30] presented an overview of the existing status and advances of various treatment methods. He stated that the anaerobic treatment was the most attractive primary treatment due to the BOD removal rate being over $80 \%$, in addition to the energy recovery in the form of biogas. His work focused on various: (1) biological methods, and (2) physico-chemical methods such as adsorption, coagulation/precipitation, oxidation, and membrane filtration. According to Satyawali \& Balakrisshnan [31] and referred by Kuusisto LM et al. [32], the anaerobic treatment of vinasse yields many benefits, including the reduction of organic compounds, a sustainable energy source to be captured as biogas, and stabilized residuals with soil amendment capabilities. Assan MADC et al. [33] evaluated the performance of vinasse aerobic digestion using rotating discs or bio discs. The efficiency of COD and of BOD removal increased with time, as the thickness of the bio film increased and at a hydraulic detention time of 3.5 days. However, the bio discs did not accomplish much in the effort of raising the $\mathrm{pH}$. His testing demonstrated that bio discs accomplish very little variations on the $\mathrm{pH}$. On his final day of testing, the $\mathrm{pH}$ varied from 6.06 to 6.76. Another downside of the treatment with bio disc is that the treatment showed variation in the volatile suspended solids values due to the occasional

Luksenberg JM et al. [34] present the following alternatives for treating the vinasse: physicochemical treatment; reverse osmosis; evaporation; incineration; industrial recycling; wetlands; stabilization lagoons; trickling filters; manufacturing of biomass; anaerobic digestion; irrigation of sugarcane fields. As previously discussed, research has been done to treat vinasse includes biological degradation, and production of lignin enzymes [35]. Wilkie [11] advocates the advantages of the anaerobic digestion because of its effective reduction of the organic load and because it produces biogas. In addition, the anaerobic digestion produces less sludge than the conventional aerobic treatment. According to Syaichurrozi et al. [36], the thermophilic anaerobic digestion of the vinasse presents a higher rate of biogas production. In addition, the organic load introduced to a thermophilic anaerobic reactor may be above $30 \mathrm{kgCOD} / \mathrm{m}^{3}$-day. Furthermore, this type of treatment has already been tested and used in many countries to treat the effluent from alcohol industries (Ribas, 2006). Professor Gatze Lettinga from Wageningen University, the Netherlands, developed the UpFlow Anaerobic Sludge Blanket (UASB) reactor in the late seventies.

Wilkie et al. [11], listed the UASB reactor as advantageous. He concluded that the thermophilic anaerobic digestion of the vinasse could be achieved in smaller reactors, in addition to having higher reaction rates.

Junior ADNF et al. [37] described the anaerobic digestion of raw vinasse at thermophilic temperatures. Although they reported initial difficulties in obtaining the sludge and even low COD removal rates, they concluded that that future optimization adjustments would improve treatment results.

\section{Various Approaches to Biogas Purification}

One of the main phases of the TAOS Process is the anaerobic digestion of the vinasse, biogas generation, and biogas purification.

The following review summarizes the main aspects of biogas purification:

The presence of non-combustible substances in the biogas, such as water and carbon dioxide, affect the burning process, making it less efficient. In addition, other contaminants may be present as is the case of hydrogen sulfide $\left(\mathrm{H}_{2} \mathrm{~S}\right)$, which can lead to early corrosion of the engine parts and appurtenances. Most anaerobic digesters produce a biogas that contains between 0.3 and $2 \% \mathrm{H}_{2} \mathrm{~S}$ and significant amounts of mercaptan, noting also the presence of traces of ammonia, nitrogen and hydrogen. Typically, the purification of biogas consists of removing the majority of the contaminants, except much of $\mathrm{CO}_{2}$, thus producing a gas with medium calorific value $(4000 \mathrm{kcal} / \mathrm{kg}$ to $6000 \mathrm{kcal} / \mathrm{kg})$ that feeds some adapted equipment [38].

It is important to remove the contaminants, before utilizing the biogas. The purification process is important for several reasons specifically because $\mathrm{H}_{2} \mathrm{~S}$ is acidic and can damage the components of the engine and $\mathrm{CO}_{2}$ (inert gas) occupies much storage space. In order to utilize the biogas as fuel for motor vehicles, the removal of $\mathrm{CO}_{2}$ is necessary because the $\mathrm{CO}_{2}$ does not contribute to the combustion process and the gas tank of the motor vehicle has limited space. Additionally, when the biogas is to be compressed to high pressures, it is important to purify the biogas, in order to avoid the unnecessary occupation of extra space in the reservoir with a non-combustible gas such as $\mathrm{CO}_{2}$. In order to convert the biogas chemical energy into another type of energy, it is necessary that the biogas characteristics be suitable for energy conversion. Grisoli et al. [38] reported the testing results of the operations run by the ENERG-BIOG, which generated electricity with turbines of $30 \mathrm{~kW}$ (ISO), using biogas from a Wastewater Treatment Plant (WWTP), supervised by the basic sanitation company of São Paulo, Brazil, SABESP (Saneamento Básico do Estado de São Paulo), in the town of 
Barueri, Brazil. It was a pioneer project in Latin America, being held in conjunction with the Biomass Users Network of Brazil (BUN), the proponent, in partnership with the National Center for Reference in Biomass (CENBIO), the executor, with the support of FINEP / CTENERG, the donor. The type of technology chosen was a 'Capstone' micro-turbine with power of $30 \mathrm{~kW}$ (ISO). In addition, they installed a 'partial' biogas purification system, which did not remove much of the $\mathrm{CO}_{2}$. Table 1 shows a comparison of results obtained by means of analysis of the biogas reported by Coelho et al. [39].

Table 1: Comparison of results from the Barueri's WWTP biogas analyses with the specifications defined by the manufacturer Capstone (CENBIO, 2003).

\begin{tabular}{|c|c|c|c|c|}
\hline Variant & Unit & Capstone (Manufacturer Specs.) & Barueri (WWTP) & Remarks \\
\hline $\mathrm{O}_{2}$ & \% Volume & 0 to 10 & 0.00 to 6.30 & Approved \\
\hline $\mathrm{e}$ & \% Volume & 0 to 50 & 0.22 to 23.8 & Approved \\
\hline $\mathrm{CO}_{2}$ & \% Volume & 0 to 50 & 25.0 to 30.8 & Approved \\
\hline $\mathrm{CH}_{4}$ & \% Volume & 30 to 100 & 44.1 to 69.9 & Approved \\
\hline $\mathrm{H}_{2} \mathrm{~S}$ & ppm vol. & 0 to 70,000 & 0.08 to 230 & Approved \\
\hline $\mathrm{H}_{2} \mathrm{O}$ (DP) & \% Volume & 0 to 5 & 0.1 to 2.8 & Approved \\
\hline P.C.I. & $\mathrm{kJ} / \mathrm{m}^{3}$ & 13,800 to 27,605 & Approved \\
\hline
\end{tabular}

Source: Coelho et al. [39].

Therefore, Coelho et al. [39] concluded that the purification system met the technical specifications required by micro-turbine. It is noteworthy that the choice and sizing of the purification and compression of the biogas need to be designed in accordance with the technical needs of the micro-turbine or other energy conversion equipment and to meet the parameters needed to safely operate the generator. Table 2 presents the analysis results performed on the micro-turbine exhaust gases, reported by Coelho et al. [39]. The data obtained from analysis of the micro-turbine exhaust gases demonstrates that the presence of NOx, was less than 1ppm. The manufacturer of the equipment (Capstone), guarantees a rate NOx emission below 9ppm. Therefore, the great advantage of using this type of technology is directly linked to environmental gain, compared with electricity generators with internal combustion (Otto Cycle), which are responsible for an emission rate of NOx in the order of 3.000ppm [39].

Table 2: Results of analysis from the micro-turbine exhaust (CENBIO, 2003).

\begin{tabular}{|c|c|c|c|c|c|c|c|}
\hline & $\mathbf{O}_{2}$ & $\mathrm{CO}_{2}$ & CO & $\mathrm{SO}_{2}$ & NO & NOx & THC \\
\hline & (\% Vol) & $(\% \mathrm{Vol})$ & (ppm) & (ppm) & (ppm) & (ppm) & $(\mathrm{ppm})$ \\
\hline Low & 18 & 2.1 & 10 & 0.001 & 0.014 & 0.162 & 42 \\
\hline High & 18.5 & 2.1 & 145 & 2.9 & 0.037 & 0.64 & 51 \\
\hline Average & 18.2 & 2.1 & 80.8 & 1.8 & 0.029 & 0.412 & 51 \\
\hline
\end{tabular}

Source: Coelho et al. [39].

According to Coelho et al. [39], the smaller generators available on the market $(30 \mathrm{~kW})$, which were the subject of their studies, require that the sewage of 88,000 population to be treated, in order to provide enough biogas to power a system of $30 \mathrm{~kW}$ operating 24 hours a day. In order to determine the generating capacity, one must take into account the load demand of the plant. In some cases, when the fare paid by the station varies according to the schedule, it may be appropriate for the installed power to be larger and the system to operate for a shorter period of time, thus reducing the consumption of the network at peak times. Additionally, one still needs to add to this figure the possibility to compute the avoided emissions of greenhouse gases $(0.5 \mathrm{tC} / \mathrm{kWh})$, therefore, including carbon credits.
The utilization of biogas energy proves to be economical as well as a sustainable practice. Additionally, depending on the biogas generating facilities, the surplus of energy may be sold to the local electricity grid. The main advantages of utilizing the biogas energy are: utilization of renewable sources, lower environmental impact, low cost and low complexity of installation, operation and maintenance. The noteworthy main advantage of using this type of technology is directly linked to environmental gain. The biogas treatment consists of removing, mainly, water vapor and $\mathrm{H}_{2} \mathrm{~S}$ through PAC. Many biogas filters utilize the photo-catalyst titanium oxide $\left(\mathrm{TiO}_{2}\right)$. Many scientists advocate the effectiveness of this photo-catalyst activated by UV or by visible light. Koziel et al. $[40,41]$ reported $\mathrm{TiO}_{2}$ as an excellent catalyst to reduce $\mathrm{H}_{2} \mathrm{~S}$ from flue gases. However, according 
to $\mathrm{Lau}$ et al. [42], $\mathrm{TiO}_{2}$ enables the production of more $\mathrm{CO}_{2}$, thus, defeating the purpose for the aforementioned treatment.

\section{Conclusions and Recommendations}

The TAOS Process has not yet been scientifically tested. Furthermore, mathematical models to estimate the quantity of the said outcomes should be developed.

The following list encompass some of the questionable aspects of the TAOS Process:

A. Scientific food tests should be performed, specifically for the presence of pesticides and fertilizing agents in the corn solid particles, before making the said cornmeal available for human consumption.

B. Calculations to predict the volume of water reclaimed per day should be performed to assess the financial feasibility of this Process.

C. Scientific fertilizer tests should be performed to assess the effectiveness of the said "mosquito-combating" fertilizer.

Figure 1 shows a process flow diagram of the TAOS treatment process

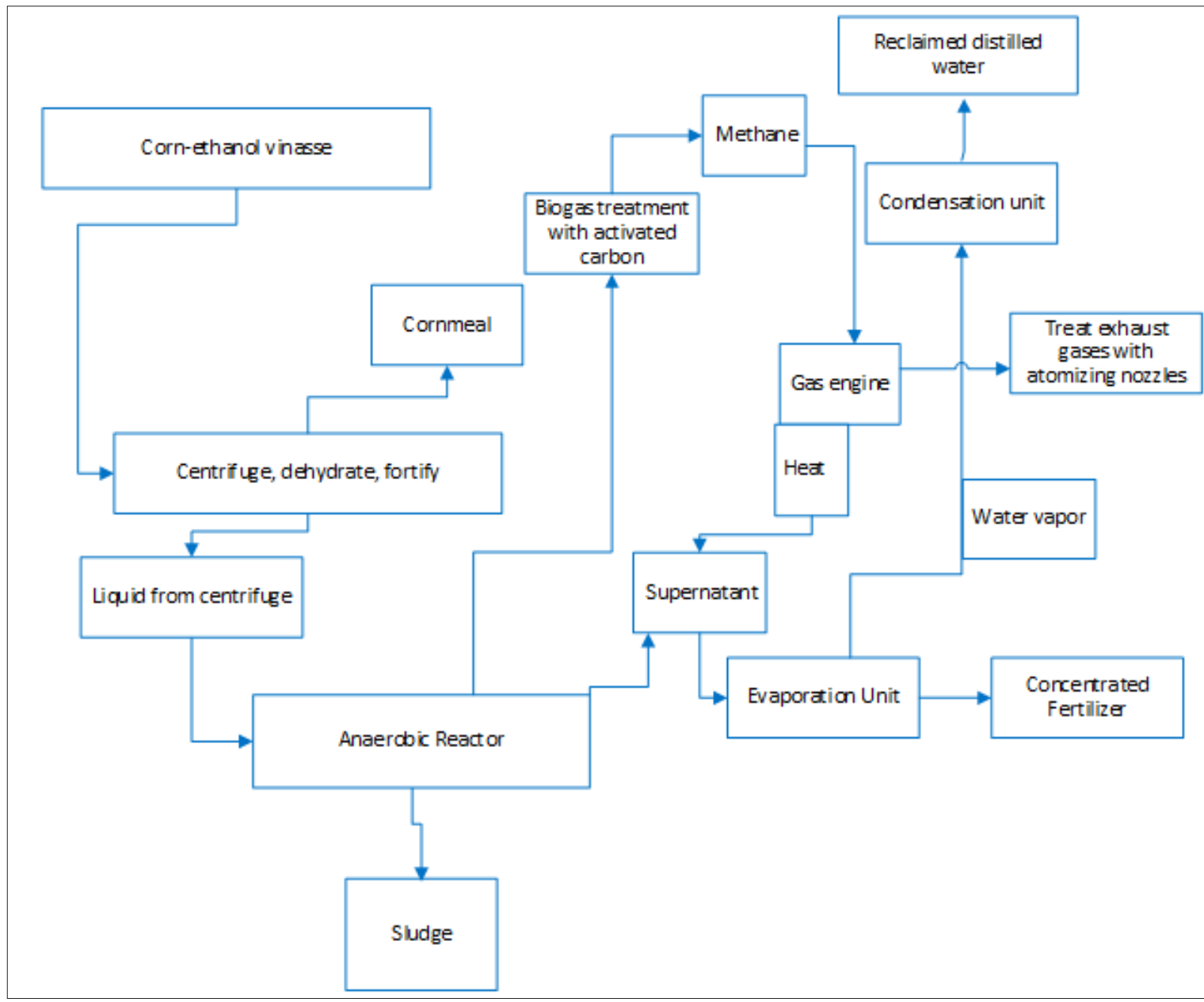

Figure 1: Diagram of the integrated TAOS process (Conceptual design by Lucina Márcia Kuusisto).

\section{Author's Contribution}

Lucina Marcia Kuusisto is the first author of this paper. She conceptualized the TAOS Treatment Process, investigated the references, and drafted the paper. In addition, she filed for patenting with the Texas A \& M University System, Commerce. Furthermore, in order to investigate the reliability and effectiveness of the TAOS Process, she applied for funding to build a prototype of the TAOS Process, to perform scientific tests, and predictive calculations.

\section{Funding}

The Author is grateful for the startup funds available through her Tenure-Track Position with the Texas A \& M UniversityCommerce.

\section{References}

1. Kuusisto, LM (2019) Integrated air-vinasse treatment-to-food, energy, water, and a novel mosquito-combatant soil amendment. Applied for 
patent with the Texas A \& M University system-commerce. Application is being reviewed. Patent has not yet been granted, USA.

2. Cristiano E, Hu Bo (2017) Vinasse from sugarcane ethanol production: better treatment or better utilization? Journal Frontiers in Energy Research 5: 1-7.

3. Milesi O (2019) Alert! hunger and obesity on the rise in Latin America for third year in a row. Food and agriculture organization of the united nations (FAO), Rome, Italy.

4. FAO (2012) The State of food insecurity in the world. Economic growth is necessary but not sufficient to accelerate reduction of hunger and malnutrition. Food and agriculture organization of the united nations (FAO), Rome, Italy.

5. Labatut B (2018) Inequality exacerbates hunger, malnutrition and obesity in Latin America and the Caribbean. Food and agriculture organization of the united nations (FAO), Rome, Italy.

6. Bishai D, Nalubola R (2002) The history of food fortification in the united states: Its relevance for current fortification efforts in developing countries. Economic Development and Cultural Change 51(1): 37-53.

7. De-Regil L, Finkelstein J, Sæterdal I, Gaitán D, Peña-Rosas J (2016) Fortification of wheat and maize flour with folic acid for population health outcomes. Cochrane Database of Systematic Reviews 4: CD012150.

8. Lancellotti C, Tur JA, Uauy (2013) Impact of folic acid fortification of flour on neural tube defects: A systematic review. Public Health Nutr 16(5): 901-911.

9. Dwyer J, Wiemer K, Dary O, Keen C, King J, et al. (2015) Fortification and health: Challenges and opportunities. Adv Nutr 6(1): 124-131.

10. Kuusisto LM (2013) Development of a mathematical model, VUMP (Vinasse Utilization for Methane Production). University of Texas at Arlington, UTA libraries, USA.

11. Wilkie AC, Riedesel KJ, Owens JM (2000) Stillage characterization and anaerobic treatment of ethanol stillage from conventional and cellulosic feedstocks. Biomass and Bioenergy 19(2): 63-102.

12. Satyawali Y, Pant D, Singh A, Srivastava RK (2009) Treatment of rayon grade pulp drain effluent by up flow anaerobic fixed packed bed reactor (UAFPBR). J Environ Biol 30(5): 667-672.

13. Bruna SB, Zaiat M, Bonomi A (2015) Anaerobic digestion of vinasse from sugarcane ethanol production in Brazil: Challenges and perspectives. Renewable and Sustainable Energy Reviews 44: 888-903.

14. Nair RB, Kabir MM, Lennartsson PR, Taherzadeh MJ, Horváth IS (2018) Integrated process for ethanol, biogas, and edible filamentous fungibased animal feed production from dilute phosphoric acid-pretreated wheat straw. Applied Biochemistry \& Biotechnology 184: 48-62.

15. Institute of Medicine (US) Committee on use of dietary reference intakes in nutrition labeling (2003) Dietary reference intakes: Guiding principles for nutrition labeling and fortification. Washington (DC): National Academies Press (US); 2003. 3, "Overview of Food Fortification in the United States and Canada, USA.

16. Ribas M, Chinalia F, Pozzi E, Foresti E (2009) Microbial succession within an anaerobic sequencing batch biofilm reactor (ASBBR) treating cane vinasse at $55^{\circ} \mathrm{C}$. Brazilian Archives of Biology and Technology 52(4): 1027-1036.

17. Vörösmarty CJ, McIntyre PB, Gessner MO, Dudgeon D, Prusevich A, et al. (2010) Global threats to human water security and river biodiversity. Nature 467: 555-551.

18. Jackson R, Carpenter S, Dahm C, McKnight D, Naiman R, et al. (2001) Water in a changing world. Ecological Applications 11(4): 1027-1045.
19. Cosgrove W, Rijsberman F (2000) World water vision. Making water everybody's business ( $1^{\text {st }}$ edn). Routledge, UK.

20. Pala M, Carvalho D, Pinto C, Sant'Anna G (2006) A suitable model to describe bioremediation of a petroleum-contaminated soil. International Biodeterioration \& Biodegradation 58(3-4): 254-260.

21. Chorom M, Sharifi H, Motamedi H (2010) Bioremediation of a crude oilpolluted soil by application of fertilizers. Iran J Environ Health Sci Eng 7(4): 319-326.

22. Verbeeck K, Buelens L, Galvita V, Marin G, Geem K, et al. (2018) Upgrading the value of anaerobic digestion via chemical production from grid injected biomethane. Journal Energy \& Environmental Science 11(7): 1788-1802.

23. Vrbová V, Ciahotný K (2017). Upgrading biogas to biomethane using membrane separation. Energy \& Fuels 31(9): 9393-9401.

24. Cortez LAB, Brossard Pérez LE (1997) Experiences on vinasse disposal: part III: Combustion of vinasse-\# 6 fuel oil emulsions. Brazilian Journal of Chemical Engineering 14(1).

25. Springer A, Goissis G (1988) Design of pond systems for treatment of ethanol plant effluents. Biological Wastes 23(2): 143-152.

26. Kerner S, Joël R, Ferrier, Valérie (2004) The treatment of wine effluents applied to small cellars: Prospects for the application of planted beds for the treatment of wine effluents. Agricultural and Viticultural Progress 121(11): 256-260.

27. Houbron E, Torrijos M, Moleta R (1998) SBR technology applied to the treatment of winery wastewaters-Results of the last three years. $2^{\text {nd }}$ international congress on the treatment of wine effluents, Application of the SBR process to wine effluents-Results of three years of monitoring, p. 8.

28. Gonçalves, Cristiane (2006) Physicochemical treatment of vinasse. XXVII Inter-American Congress on Sanitary and Environmental Engineering, Brazil.

29. Fernández N, Polanco F, Montalvo SJ, Toledano D (2001) Use of activated carbon and natural zeolite as support materials, in an anaerobic fluidised bed reactor, for vinasse treatment. Water Sci Technol 44(4): 1-6.

30. Tewari PK, Batra VS, Balakrishnan M (2007) Water management initiatives in sugarcane molasses-based distilleries in India. Resources, Conservation and Recycling 52(2): 351-367.

31. Satyawali Y, Balakrishnan M (2008) Wastewater treatment in molassesbased alcohol distilleries for COD and color removal: A review. Journal of Environmental Management 86(3): 481-497.

32. Kuusisto LM, Sattler ML, Chen VCP (2019) Predicting Bioenergy potential from vinasse digestion: The VUMP Model (Vinasse Utilization for Methane Production). J Civil Eng Urban 9(4): 36-42.

33. Assan, André de Carvalho M (2006) Evaluation of the performance of a biological reactor of rotating discs, biodisks, in the treatment of effluents from the sugar and alcohol industry. Postgraduate Department in Environmental Technology, University of Ribeirão Preto, Brazil.

34. Luksenberg JM, Sá A, Durso MN (1980) Process for the production of fuel alcohol, without vinasse. Descriptive Report of the invention patent. Dyna Engenharia SA, São Paulo, Brazil.

35. Pant D, Alok Adholeya (2007) Enhanced production of ligninolytic enzymes and de-colorization of molasses distillery wastewater by fungi under solid state fermentation. Biodegradation 18(5): 647-659.

36. Syaichurrozi, Budiyono, Sumardiono S (2013) Predicting kinetic model of biogas production and biodegradability organic materials: Biogas production from vinasse at variation of COD/N ratio. Bioresour Technol 149: 390-397. 
37. Júnior ADNF, Koyama MH, de Araújo Júnior MM, Zaiat M (2016) Thermophilic anaerobic digestion of raw sugarcane vinasse. Renewable Energy 89: 245-252.

38. Grisoli R, Coelho S, Jose Goldemberg CENBIO (2011) Personal communication with REN21.CENBIO.

39. Coelho ST, Velázquez SMSG, SILVA OCD (2006) Generation of electric energy from biogas from sewage treatment. Proceedings of the 6. Energy Meeting in Rural Areas.

40. Koziel JA, Cai L, Wright DW, Hoff SJ (2006) Solid phase microextraction as a novel air sampling technology for improved, GC-Olfactometry- based, assessment of livestock odors. J Chromatogr Sci 44(7): 451-457.

41. Kummu M, Guillaume JH, de Moel H, Eisner S, Flörke M, et al. (2016) The world's road to water scarcity: shortage and stress in the $20^{\text {th }}$ century and pathways towards sustainability. Scientific Reports 6: 1-16.

42. Lau, Ngai Ting (2006) Catalytic reduction of sulfur dioxide and nitric oxide. The Institute for Environment and Sustainable Development. The Hong Kong University of Science and Technology, IENV Conference Paper, Hong Kong. 